Institute of $\mathbf{F}_{\text {ood and }} \mathbf{A g r i c u l t u r a l}_{\text {ciences }}$

\title{
Housing As We Grow Older: Taking Stock ${ }^{1}$
}

Virginia Peart and Carolyn Wilken ${ }^{2}$

Are you a go-go, a slow-go, or a no-go? Do you like to get out every day? Do you prefer to visit in your home? Do you like a lot of space in your home? Do you prefer a smaller, easier to care for living area? As people grow older, their interests and abilities change. Their housing needs also change.

Your home affects how you live in ways you may not realize. Most people prefer to stay in their own homes for as long as possible. However, as the years go by, you may find that another housing option is best for you. Stairs may become more difficult to climb. An extra room may become space that costs more to heat and maintain.

There are many housing options that may fit your changing needs as you grow older. What is right for a go-go (a person who is always on the go) may not be the best choice if you've become a slow-go, or especially a no-go. Now is the time for you to take stock.

\section{To Change Your Housing or Not to Change}

How do you choose your best housing options? Begin planning as soon as possible, before an emergency forces you to choose quickly. If you want to stay in your home, look at how it is designed. Take some time to learn what you really need to make your home safe, comfortable and convenient.

\section{Here are some questions you can ask yourself:}

- Is the bathroom large enough for someone to help me if needed?

- Are the doorways wide enough for a wheelchair or walker?

- Are all the rooms on one floor? If not, is there a bedroom and bathroom on the first floor?

1. This document is Fact Sheet FCS 3187, a series of the Department of Family, Youth and Community Sciences, Florida Cooperative Extension Service, Institute of Food and Agricultural Sciences, University of Florida. Publication date: November 2002. First published: January 1994. Revised: November 2002. Originally published as SAH-1 and adapted for use in Florida from "Planning Ahead for Elder Care: Decisions About Housing" prepared by Glenda Herman and Sandra Zaslow, Extension Housing Specialists, North Carolina Extension Service and "Long-Term Care: Services for the Individual" prepared by the American Council of Life Insurance. Please visit the EDIS web site at http://edis.ifas.ufl.edu

2. Adapted by Virginia Peart, former associate professor, Housing; revised by Carolyn Wilken, associate professor, Family Life; and reviewed by Nayda I. Torres, professor, Family and Consumer Economics, Department of Family, Youth and Community Sciences, Cooperative Extension Service, Institute of Food and Agricultural Sciences, University of Florida, Gainesville, 32611. 
- Will I be able to take care of the house and yard?

- Will I be able to pay the taxes, insurance and utilities on my retirement budget?

- Are programs available which could help reduce housing costs?

- What services are available in my community: health care, home care, meals, etc.?

- Is the house close to family and friends?

- Is it close to community services and recreational facilities?

- Is the house safe? Does it have good locks and burglar and smoke alarms? Is it close to neighbors who will help?

- Is the neighborhood still a safe place to live?

\section{Some reasons to stay in your home could be:}

- You own your home or the mortgage is almost paid off.

- You can afford to live there comfortably on a fixed income. (Will your income increase as costs go up?)

- Your friends and family live close enough to visit often.

- You're active in local social and religious groups.

- Dependable transportation services are available.
- You can make arrangements for a companion if you want or need one.

\section{Some reasons why you might want to move are:}

- The house is too big now that your children have left home or now that your spouse is no longer living.

- Your friends are gone and you no longer feel at home in the neighborhood.

- Your children live too far away to visit often.

- There are no recreational facilities in the neighborhood.

- It's hard to shop for groceries, clothing and other necessities because stores are too far away.

- Dependable transportation is not readily available and you don't know how much longer you will be able to drive yourself.

- You cannot afford to live there on a fixed income.

- For health reasons, you shouldn't live alone.

\section{Take Time -- Do It Right}

Many housing choices are available for older adults and their families. Your choices are not limited to staying at home alone, living with a grown child or living in a nursing home.

You may choose to live in your present home or to move. Housing options include: 
a single family home, a duplex, a

manufactured home, an apartment, a hotel or a group facility for elders.

Whether you plan to stay in your home or move, find out what long-term care services are available. These services can help you be more independent even with a chronic illness or disability. Some of these services are described below.

\section{Home-Based Services}

Many services, such as nursing, medical, and social services, can be provided at home. The biggest advantage of care at home is that it provides an alternative to a nursing home or other long-term care facility. Most people would prefer to stay at home, if possible. At home, they can be more independent and be closer to family and friends. Some common home care services are described below.

- Home Health Care services may include skilled nursing care, health monitoring and evaluation, dispensing medication, physical and other types of therapy, psychological counseling and teaching individuals or families about ongoing care. These services are often provided under a nurse's or doctor's supervision.

- Homemaker Services are available to help with many essential household tasks such as food shopping, preparing meals, light housekeeping and laundry.

- Chore Services are available to help with heavy-duty tasks, such as floor or window washing, minor home repairs, yard work, and other types of home maintenance.
- Home-delivered Meals, often called "Meals-On-Wheels" can be delivered five or more days a week to individuals who cannot shop and cook on their own. These services can provide better nutrition and a sense of security for the homebound.

- Companion Services, whether paid or volunteer, ease loneliness for the homebound. Services can range from supervision to simple companionship.

- Companion services may also include Respite Care, which gives family members a break from their care giving responsibilities for a short period of time. Respite care is also available in some adult day care centers, hospitals, and nursing homes.

- Telephone Reassurance, regularlyscheduled calls to the homebound, is provided by some agencies and volunteer organizations. These calls help ensure personal safety and help reduce social isolation.

- Emergency Response Systems link an individual to a fire department, hospital, other health facility, or social service agency. Simply pressing a button triggers a communicator attached to the telephone which automatically calls the response center.

- Transportation and Escort Services are available to help frail or disabled individuals get to medical or therapy appointments, or go shopping or banking. 
- Home Observation Programs can increase the health and safety of the elderly and the homebound. Letter carriers and others who make regular visits to residential areas look for signs that may mean the resident is ill or has had an accident and alert social service agencies. These programs are available in many communities under a variety of names, sponsored by a variety of companies.

\section{Consider, Consider, Consider}

It is best to make future housing decisions while you are in good health. It is also important to discuss these plans with the family member(s) or friend(s) who may be called on to help arrange for your care.

Some people feel that age-segregated housing and the loss of a certain amount of independence will reduce their mental and physical well-being. Others enjoy the social activities that are available in age-segregated housing and can choose to spend time in their own apartments or rooms when they want time alone. Think about which would be best for you.

Explore the housing choices in or near your community. This can take some time. It is important that you begin early. Look around and ask questions. Talk to friends and acquaintances with similar needs who have made changes in where they live. Be sure to include finances in your planning.

Here are some ideas that may help you select the best retirement housing choice for you.
- If you are considering moving to a new community, subscribe to the local newspaper. It may help you learn about the area and decide whether it would be a good choice for you.

- If you are thinking about a change of climate, visit the new location at the worst, as well as the best, possible time of the year.

- If you think you would like to live with relatives, visit their home for two or three weeks to see if this arrangement would work for all.

- If you plan to move to an apartment or a community designed for retirees, talk to residents about the quality and cost of the facility as well as the cost of utilities, taxes, and other services.

- If you plan to stay where you are now, ask others who have remained in their homes for advice to help you plan realistically. Check with your local Council on Aging or Senior Center to learn what kinds of services are available, their cost, and eligibility requirements.

- Before signing any contracts or leases, be sure you fully understand your rights and responsibilities and what services will be provided under those agreements.

- Learn as much as possible about the management of the facility and how much input you would have as a resident.

- Try to determine how flexible the facility would be in meeting your needs as they change over time. 
- Be sure you understand the commitments involved in any life-care contacts.

\section{Your Responsibility for Future Housing Decisions}

You cannot know what your health care needs and your exact financial situation will be. But you can plan for future housing needs.

As you start gathering information on what is available in your community, talk over your wants and needs with family members or friends. At least one person (family member, friend, lawyer or bank trustee) should be fully aware of your personal wants and be willing, if necessary, to carry out your plans if you are no longer able to. Think carefully about who you will entrust with this responsibility. Avoid asking for or making promises that may not be possible to keep. Select a second and a third person and have the appropriate documents prepared to give legal authority to the person(s) you choose.

In addition to making housing choices, you will also need to consider who you want to live with. Are you happy alone or would you rather live with a family member, relative or friend?

\section{Housing Decisions...For Yourself}

To help you decide where to live as you grow older:

1. Plan ahead -- plan now!

2. Evaluate where you live now.
3. Talk with family members.

4. Decide whether to live alone or with others.

5. Choose from housing options:

- independent units

- multi-unit facilities

- service-oriented or health-care facilities

6. Gather information about the various housing types in or near your community. Learn about community housing assistance programs.

7. Evaluate your financial situation and get legal help as needed.

\section{Housing Decisions...For Another}

To help an aging family member decide where to live:

1. Plan ahead -- plan now!

2. Help family members realistically evaluate where they live now.

3. Discuss options fully and be sure to listen.

4. Be sure the housing choice meets the physical and mental needs of the aging family member.

5. Think about the physical, mental and financial resources that you and others have to help an older family member. 
6. Gather information about the types of housing available in the community and about housing assistance programs.

7. Help older family members find competent financial and legal advice.

\section{Make Your Housing Work for You}

Whatever type of housing you choose, you should evaluate it for accessibility and adaptability. An adaptable living space may have built-in features, such as wider doors and clear floor space, that were included in construction. Other features, such as wall reinforcement for grab bars at tubs and toilets and removable base cabinets for knee space, may be added as needed in the future. Adaptable housing allows features in the house to be adjusted to meet varied needs over time. 